\title{
GUALIDADE TECNOLÓGICA DE MASSAS ALIMENTÍCIAS FRESCAS ELABORADAS DE SEMOLINA DE TRIGO DURUM (T. durum L.) E FARINHA DE TRIGO (T. aestivum L.) ${ }^{1}$
}

\author{
Yoon Kil CHANG ${ }^{2, *}$, Héctor Eduardo Martínez FLORES ${ }^{3}$
}

\begin{abstract}
RESUMO
Foram elaboradas massas alimentícias frescas utilizando as seguintes proporções de semolina de trigo durum e farinha de trigo comum: 100:0, 80:20, 60:40, 40:60; 20:80 e 0:100, respectivamente. As massas foram embaladas em sacos plásticos com propriedades de impermeabilidade a água, e armazenadas a $4^{\circ} \mathrm{C}$. No dia da preparação (dia 0) e nos dias 1,2 e 3, foram avaliados o tempo de cozimento, aumento de volume, ganho de peso, perda de sólidos solúveis e textura (firmeza) das massas. As massas preparadas com porcentagens acima de $60 \%$ de semolina de trigo durum apresentaram melhores características no tempo de cozimento, firmeza e intensidade da cor amarela. Os 3 dias de armazenamento não influenciaram de forma significativa $(\mathrm{p}<0.05)$ as características de qualidade das massas. Palavras-chave: massas alimentícias; semolina; tempo de cozimento; textura.
\end{abstract}

\section{SUMMARY}

GUALITY OF FRESH PASTAS OBTAINED FROM BLENDS OF DURUM WHEAT SEMOLINA (T. durum L.) AND WHEAT FLOUR (T. aestivum L.). Fresh pastas using the following proportions of durum wheat semolina and wheat flour: 100:0, 80:20, 60:40, 40:60; 20:80 and 0:100, respectively, were prepared. The pastas were stored at $4^{\circ} \mathrm{C}$ in plastic bags with barrier properties to water steam. In the days 0 (preparation day), 1, 2 and 3, the cooking-time, volume increase, weight gain, cooking solids loss, and texture (firmness) of fresh pastas were evaluated. The fresh pastas elaborated with at least $60 \%$ of durum wheat semolina, showed the best characteristics for cookingtime, firmness and intensity of yellow color. The three days of storage did not affect $(\mathrm{p}<0.05)$ the quality characteristics of pastas. Keywords: food pastas; semolina; cooking-time; texture.

\section{1 - INTRODUÇÃO}

Existem três tipos genéticos de trigos cultivados comercialmente: Triticum durum (usado para elaboração de massas alimentícias), Triticum aestivum (usado para produção de pães, bolos e biscoitos) e Triticum compactum (usado na elaboração de biscoitos suaves) [20]. O endosperma do T. durum L (trigo durum) é mais duro que o do Triticum aestivum, apresentando maiores niveis de cinzas e proteínas. A farinha de Triticum durum tem coloração amarelada devido à presença de pigmentos carotenóides e tem qualidade de glúten que possibilita a produção de massas alimentícias. A massa fresca produzida a partir da semolina de Triticum durum apresenta ótimas características de qualidade, tais como: textura firme após o cozimento, e sem adesividade excessiva [9].

Embora o trigo durum seja considerado a melhor matéria-prima, para a produção de massas alimentícias, o uso de outro trigo é permitido em alguns países, tais como o Canadá e os Estados Unidos, e depende, principalmente, da disponibilidade da semolina

\footnotetext{
Recebido para publicação em 11/11/1999. Aceito para publicação em 27/10/2004 (000394).

2. Departamento de Tecnologia de Alimentos - Faculdade de Engenharia de Alimentos - UNICAMP - C.P. 6121, CEP 13083-970, Campinas, SP.

3. Centro de Investigación en Ciencia Aplicada y Tecnología Avanzada del I.P.N. José Siurob no. 10, Colonia Alameda. Querétaro, Qro., México. Caixa Postal 76040, Telefone/Fax: 0055 (42) 12-9466 Escuela de Quimicofarmacobiología. Universidad Michoacana de San Nicolás de Hidalgo. Tzintzuntzan 173. Col. Matamoros. C.P. 58240. Morelia, Mich., México. E-mail: hedu65@yahoo.com.br

* A quem a correspondência deve ser enviada.
}

do trigo durum. Em diversos países consumidores de massas alimentícias dependentes da importação de trigo durum, para atender a demanda interna, tornase necessário o uso de trigos nacionais disponíveis como matéria-prima para a produção de massas alimentícias.

Atualmente, no Brasil, o trigo durum não é cultivado [19]; portanto, o trigo comum é a matéria-prima mais comumente empregada para a produção de massas alimentícias, correspondendo a cerca de $85 \%$ da produção nacional das massas. As massas preparadas a partir de farinha de trigo comum não apresentam as características de qualidade das massas preparadas com trigo durum, portanto é necessário fazer algumas adaptações na formulação de massas preparadas com trigo comum. Uma outra alternativa para melhorar os atributos de qualidade das massas alimentícias feitas com semolina de trigo comum, é incorporar proporções adequadas de semolina de trigo durum na farinha de trigo comum.

O objetivo do presente trabalho foi estudar o efeito da adição da semolina de trigo durum (T. durum L.) à farinha de trigo (T. aestivum L.), nos parâmetros de qualidade e vida-de-prateleira da massa fresca.

\section{2 - MATERIAIS E MÉTODOS}

\section{1 - Matéria-prima}

Foram utilizadas neste estudo a farinha de trigo linha tenro (Cargill Extra) e semolina de trigo durum (Cargill Speciale), fornecidas pela CARGILL FOODS. A semolina de trigo durum será denominada STD e a farinha de trigo - linha tenro FT. 


\section{2 - Composição centesimal, cor e granulometria da matéria-prima}

Nas farinhas, foram determinados os teores de umidade, proteína, e cinzas, usando os métodos 44-15A, 46-13, e 08-01, da AACC [1]. Os lipídios foram determinados com o método de BLIGH \& DYER [6].O parâmetro $b$ da cor foi determinado em espectrofotômetro, modelo Color Quest II, marca Hunter Lab. A fibra alimentar foi determinada usando o método de PROSKY et al. [26 ].

A granulometria foi determinada colocando $100 \mathrm{~g}$ de amostra no aparelho Produtest, equipado com 6 peneiras, com aberturas de 1,0mm (US no 20), 0,42mm (US no 40), 0,25mm (US no 60), 0,177mm (US nº 80), e 0,149mm (US no 100). O tempo de vibração foi de $20 \mathrm{~min}$. As frações das farinhas retidas nas peneiras foram pesadas, e os resultados obtidos, expressos em porcentagem.

\section{3 - Mistura das farinhas e avaliação de suas pro- priedades reológicas}

As misturas foram preparadas utilizando-se as seguintes proporções de STD e FT: 100:0, 80:20, 60:40, 40:60; 20:80 e 0:100.

As propriedades viscoamilográficas foram determinadas pelo método de PANOZZO \& MCCORMICK [25]; as farinográficas, segundo o método 54-21 da AACC [1], com modificações propostas por IRVINE, BRADLEY \& MARTIN [22]; as alveográficas, usando o método 54-30 da AACC [1]; a quantidade de glúten úmido e seco foram determinados de acordo com o método 38-12 da AACC [1].

\section{4 - Processamento das massas alimentícias}

As amostras foram acondicionadas com água destilada até se obter uma massa com umidade final de $32,5 \%$. A massa de cada tratamento foi processada na máquina extrusora Pastaia II. Os fios de massa fresca extrusados foram cortados em um comprimento de $26 \mathrm{~cm}$, embalados em sacos plásticos com boa barreira à água, e armazenados na geladeira a $4^{\circ} \mathrm{C}$, para avaliação da vida-de-prateleira. A embalagem tinha a seguinte composição: camada externa de polipropileno bi-orientado (BOPP) de $25 \mu \mathrm{m}$ de espessura e camada interna de polipropileno comum (PP) de $30 \mu \mathrm{m}$ de espessura, fornecido pela ITAP - BEMIS (Associação Dixie Toga Bemis).

A prensa da extrusora tinha as seguintes características: taxa de compressão: 1:1; trafila com formato de espaguete com orifícios de $1,8 \mathrm{~mm}$ de diâmetro revestidos internamente com teflon.

\section{5 - Análise dos produtos}

\subsection{1 - Umidade e cor}

A umidade das massas foi determinada segundo o método no 44-15A da AACC [1]. A cor das massas foi determinada de acordo com a metodologia anteriormente descrita para farinhas.

\subsection{2 - Teste de cozimento}

O teste de cozimento foi realizado segundo o método nำ16-50 da AACC [2]; os parâmetros avaliados foram:

\section{- Tempo de cozimento}

Determinou-se pela cocção de $10 \mathrm{~g}$ de amostra em $140 \mathrm{~mL}$ de água destilada em ebulição, até atingir o tempo de cozimento, o qual foi caracterizado pela gelatinização do amido em toda seção da massa. Este ponto foi determinado pela compressão do produto cozido entre duas lâminas de vidro até o desaparecimento do eixo central, a cada minuto, após 5min. de cozimento.

- Ganho de peso e aumento de volume

O aumento de peso foi determinado pela pesagem de $\log$ de massa antes e após a cocção, usando-se o tempo de cozimento ideal de cada amostra. Os valores foram expressos em número de vezes que a massa aumentou de peso após o cozimento.

Determinou-se o aumento de volume das massas antes e após o cozimento. As amostras foram imersas em 140mL de hexano; mediu-se então o volume de hexano deslocado pela massa crua e cozida. Os resultados foram expressos em número de vezes que a massa aumentou de volume após a cocção.

- Perda de sólidos solúveis ou resíduo na água de cozimento

A quantidade de sólidos perdidos na água de cozimento foi determinada pela evaporação de $25 \mathrm{~mL}$ de amostra em estufa a $110^{\circ} \mathrm{C}$ até peso constante.

\section{- Textura (firmeza)}

A firmeza das massas alimentícias foi avaliada utilizando o texturômetro TA-XT2 Texture analyzer (Stable Micro Systems, Haslemer, Surrey, England).

As massas frescas com $5 \mathrm{~cm}$ de comprimento foram cozidas de acordo com o tempo ideal de cozimento. Após 15 min de resfriamento, as massas foram lavadas e escorridas, e, posteriormente submetidas ao teste. Para o teste, foi utilizada a aditamento P/35 (cilindro de $35 \mathrm{~mm}$ ) usando $5 \mathrm{~kg}$ de carga. A massa fresca foi comprimida em $75 \%$ da sua área a uma velocidade de compressão de $2,0 \mathrm{~mm} / \mathrm{s}$. O valor de pico máximo da curva foi considerado como a firmeza do produto, e expresso em kgf.

\section{3 - RESULTADOS E DISCUSSÃO}

\section{1 - Composição centesimal, cor e granulometria da matéria-prima}

Maior conteúdo de proteína, cinzas, lipídios e maior intensidade de cor foi apresentada na semolina de trigo durum (STD) em relação à farinha de trigo tenro linha tenro (FT) (Tabela 1). 
O teor de proteína para a STD foi de 14,03\%, enquanto que para a FT foi de $12,47 \%$. O teor de proteína da amostra de STD está dentro dos padrões registrados na literatura $[12,13,23]$. É importante ressaltar o maior conteúdo de proteínas na STD, pois isso é associado a uma melhor qualidade do cozimento do macarrão [9, 24].

O teor de cinzas da STD foi de $0,93 \%$, enquanto que a FT apresentou um conteúdo de $0,40 \%$. O conteúdo de cinzas encontra-se diretamente relacionado com o grau de extração e rendimento da semolina durante a moagem. Farinhas que apresentam maior teor de cinzas possuem um maior grau de extração da semolina, mas também apresentam partículas maiores de farelo e tendem a apresentar coloração mais escura. Para algumas indústrias de moagem, o teor de cinzas é considerado a principal característica do trigo durum. Em alguns países, como Itália, a semolina de primeira qualidade tem que conter menos de $0,90 \%$ de cinzas [5]. A STD analisada, neste estudo, teve um conteúdo de $0,93 \%$, valor maior em 3,3\% ao valor recomendável, para a preparação de massas alimentícias usando semolina [15]. Uma maior porcentagem de cinzas, superior a $0,90 \%$, significa que tem material não desejável, como o farelo, o qual pode refletir-se em uma menor qualidade textural e sensorial do produto final [8].

A STD teve maior conteúdo de lipídios $(0,51 \%)$ em relação a FT $(0,32 \%)$, resultados que concordam com os registrados por TOEPFER et al. [28].

A cor amarela, representada pelo parâmetro $b$, mostra maior intensidade na amostra de STD $(18,35)$ em relação à amostra FT $(9,86)$. A cor amarela é uma característica desejada das variedades de trigo durum, e os componentes responsáveis pela cor são o caroteno e a luteína.

TABELA 1. Composição centesimal e cor da farinha e semolina.

\begin{tabular}{|c|c|c|c|c|c|c|}
\hline Farinhas & Proteína $^{1}$ & Cinzas $^{1}$ & Lipidios $^{1}$ & $\begin{array}{c}\text { Fibra } \\
\text { dietética }^{1}\end{array}$ & Carboidratos $^{2}$ & $\begin{array}{l}\text { Cor }^{3} \\
\text { (b) }\end{array}$ \\
\hline $\begin{array}{l}\text { Farinha de } \\
\text { Trigo }\end{array}$ & $12,47 b$ & $0,40 b$ & $0,32 b$ & $0,52 b$ & $86,29 a$ & $9,86 b$ \\
\hline $\begin{array}{l}\text { Semolina de } \\
\text { Trigo durum }\end{array}$ & $14,03 a$ & $0,93 a$ & $0,51^{\mathrm{a}}$ & $0,93 a$ & $83,60 a$ & $18,35 a$ \\
\hline
\end{tabular}

Na Tabela 2, pode-se observar que $52,45 \%$ das partículas de STD foram retidas na peneira US no 80 $(0,177 \mathrm{~mm})$, enquanto que $78,58 \%$ das partículas de FT apresentaram tamanho de partícula menor que $0,149 \mathrm{~mm}$ (peneira US n⿳0 100).

A distribuição de partículas para a amostra de STD foi diferente $(p<0.05)$ em relação às semolinas comerciais usadas na produção de pastas, de acordo com os registros de alguns pesquisadores [18, 29]. Nessas semolinas, a maior parte das partículas (51,6-61,5\%) ficam retidas na peneira US no $60(0,250 \mathrm{~mm})$. Na semo- lina usada neste estudo, a maior parte das partículas $52,45 \%$ - ficou retida na peneira US no $80(0,177 \mathrm{~mm})$, e $15,67 \%$ atravessaram a peneira US no $100(<0,149 \mathrm{~mm})$. As especificações com relação à granulometria da semolina variam em cada país. Nos E.U.A., segundo BANASIK [4], a semolina comercial não deve conter acima de $3 \%$ de partículas de farinha passando pela peneira US no $100(0,149 \mathrm{~mm})$, e no Canadá, segundo DEXTER, MATSUO \& MORGAN [14] a semolina deve conter menos que $1 \%$ passando pela peneira US no 100 $(0,149 \mathrm{~mm})$.

TABELA 2. Distribuição de tamanho de partículas da farinha de trigo e semolina.

\begin{tabular}{cccc}
\hline $\begin{array}{c}\text { Peneira } \\
\left(\text { US n }^{\circ} .\right)\end{array}$ & $\begin{array}{c}\text { abertura } \\
(\mathrm{mm})\end{array}$ & $\begin{array}{c}\text { Farinha de trigo } \\
(\%)\end{array}$ & $\begin{array}{c}\text { Semolina de trigo durum } \\
(\%)\end{array}$ \\
\hline 20 & 1,00 & $0,00 \mathrm{c}$ & $0,00 \mathrm{e}$ \\
40 & 0,420 & $0,28 \mathrm{c}$ & $0,02 \mathrm{e}$ \\
60 & 0,250 & $0,27 \mathrm{c}$ & $24,43 \mathrm{~b}$ \\
80 & 0,177 & $9,66 \mathrm{~b}$ & $52,45^{\mathrm{a}}$ \\
100 & 0,149 & $11,23 \mathrm{~b}$ & $7,43 \mathrm{~d}$ \\
$>100$ & $<0,149$ & $78,58 \mathrm{a}$ & $15,67 \mathrm{c}$ \\
\hline
\end{tabular}

Letras diferentes na mesma coluna são estatisticamente diferentes $(\mathrm{p}<0.05)$ ${ }^{1}$ Material retido sobre a peneira.

\section{2 - Teor de glúten úmido e seco e, cor das farinhas}

À medida em que aumentou o nível de substituição de STD por FT, tanto o teor de glúten úmido quanto o de seco aumentaram, (Tabela 3). Os teores de glúten úmido e seco foram de $27,81 \%$ e $9,58 \%$, respectivamente, na FT, e de $34,52 \%$ e $11,74 \%$, respectivamente, para a STD. CUBBADA [9] menciona que um conteúdo elevado de glúten está associado com a boa qualidade do cozimento de massas alimentícias. Na literatura é reportado que valores acima de $25 \%$ de glúten úmido já é considerado de boa qualidade [11, 16].

Os valores da cor amarela dos diversos tratamentos tiveram incremento substancial da intensidade de cor a medida em que se aumentou o nível de substituição de STD na FT (Tabela 3).

TABELA 3. Teores (\%) de glúten úmido e seco e, cor nas misturas da farinha e semolina.

\begin{tabular}{cccc}
\hline \multirow{2}{*}{ FT/STD $^{1}$} & \multicolumn{2}{c}{ Glúten } & $\begin{array}{c}\text { Cor } \\
\text { parâmetro } b\end{array}$ \\
\cline { 2 - 3 } & úmido & seco & para, \\
\hline $100 / 0$ & $27,81 \mathrm{e}$ & $9,58 \mathrm{f}$ & $9,86 \mathrm{f}$ \\
$80 / 20$ & $28,27 \mathrm{e}$ & $10,09 \mathrm{e}$ & $11,46 \mathrm{e}$ \\
$60 / 40$ & $30,50 \mathrm{~d}$ & $10,46 \mathrm{~d}$ & $13,09 \mathrm{~d}$ \\
$40 / 60$ & $31,24 \mathrm{c}$ & $10,87 \mathrm{c}$ & $15,08 \mathrm{c}$ \\
$20 / 80$ & $32,56 \mathrm{~b}$ & $11,42 \mathrm{~b}$ & $16,65 \mathrm{~b}$ \\
$0 / 100$ & $34,52 \mathrm{a}$ & $11,74 \mathrm{a}$ & $18,35 \mathrm{a}$ \\
\hline
\end{tabular}

Letras diferentes na mesma coluna são estatisticamente diferentes $(\mathrm{p}<0.05)$. FT / STD. Farinha de trigo / semolina de trigo durum.

\section{3 - Parâmetros farinográficos}

As características farinógraficas da massa de semolina são determinadas na faixa de absorção de 26,5 
a 36\%, que é usada na elaboração de massas comerciais [17]. De acordo com testes preliminares, foi encontrado que a medição dos parâmetros farinógraficos neste estudo foi feita com porcentagem de absorção de água fixa em $32,5 \%$.

De acordo com os parâmetros obtidos das curvas farinográficas, a FT usada neste estudo pode ser classificada como do tipo II (tempo de chegada curto e longa estabilidade) e da STD do tipo I (tempo de chegada curto e curta estabilidade), de acordo com a classificação de D’APPOLONIA [10]. Em seguida, são discutidos alguns desses parâmetros farinográficos.

Conforme aumentou a proporção de STD para FT, houve aumento no valor de absorção de água (Tabela 4). Para a FT o valor foi de 59,7\%, enquanto para a STD foi de 64,0\%. O aumento na absorção de água na STD e, conseqüentemente, nas misturas contendo maiores porcentagens de STD, pode ser atribuído provavelmente ao maior conteúdo de proteína [22]. Entretanto, alguns trabalhos registram que a absorção de água de semolinas de trigo durum é maior que a de trigo comum, não somente devido ao maior conteúdo de proteína, mas, também provavelmente ao maior conteúdo de amido danificado [3, 7].

O tempo de chegada, que indica o tempo necessário para a mistura (farinha-água) atingir a consistência específica, e o tempo de desenvolvimento, que indica a qualidade protéica, aumentaram quando foi acrescentada a porcentagem de STD nas misturas. A correlação entre o tempo de desenvolvimento e o maior conteúdo protéico de farinhas foi registrado por RAHIM et al. [27], e DEXTER \& MATSUO [12].

A estabilidade das massas, que indica o tempo que a farinha mantém a consistência específica durante o amassamento, diminuiu conforme aumentou o nível de substituição da STD para a FT. Em contrapartida, o tempo de saída, que determina o tempo máximo que a mistura deve ser amassada para manter a consistência específica, diminuiu quando a porcentagem de STD foi incorporada em maiores porcentagens para a FT. Os tempos de saída para a FT e STD foram de 16 e 6,5min., respectivamente.

TABELA 4. Parâmetros farinográficos das misturas de farinha e semolina.

\begin{tabular}{cccccc}
\hline FT/STD & $\begin{array}{c}\text { Absorção de } \\
\text { água a 500UF } \\
(\%)\end{array}$ & $\begin{array}{c}\text { Tempo de } \\
\text { chegada } \\
(\mathrm{min})\end{array}$ & $\begin{array}{c}\text { Tempo de } \\
\text { desenvolvimento } \\
\text { (min) }\end{array}$ & $\begin{array}{c}\text { Estabilidade } \\
\text { (min) }\end{array}$ & $\begin{array}{c}\text { Tempo } \\
\text { de saída } \\
(\mathrm{min})\end{array}$ \\
\hline $100 / 0$ & $59,7 \mathrm{c}$ & $1 \mathrm{~b}$ & $2 \mathrm{~b}$ & $15^{\mathrm{a}}$ & $16 \mathrm{a}$ \\
$80 / 20$ & $61,6 \mathrm{~b}$ & $1 \mathrm{~b}$ & $2 \mathrm{~b}$ & $11,5 \mathrm{~b}$ & $12,5 \mathrm{~b}$ \\
$60 / 40$ & $61,9 \mathrm{~b}$ & $1 \mathrm{~b}$ & $2 \mathrm{~b}$ & $9,5 \mathrm{c}$ & $10,5 \mathrm{c}$ \\
$40 / 60$ & $63,0 \mathrm{ab}$ & $1 \mathrm{~b}$ & $2 \mathrm{~b}$ & $9 \mathrm{c}$ & $9,0 \mathrm{~d}$ \\
$20 / 80$ & $62,9 \mathrm{ab}$ & $1,5 \mathrm{a}$ & $2,5 \mathrm{a}$ & $6 \mathrm{~d}$ & $7,5 \mathrm{e}$ \\
$0 / 100$ & $64,0 \mathrm{a}$ & $1,5 \mathrm{a}$ & $2,5 \mathrm{a}$ & $6,5 \mathrm{~d}$ & $6,5 \mathrm{e}$ \\
\hline
\end{tabular}

Letras diferentes na mesma coluna significa que são estatisticamente diferentes $(\mathrm{p}<0.05)$.

${ }_{1 .}^{1 .}$ FT / STD. Farinha de trigo / Semolina de trigo durum.

\section{4 - Parâmetros alveográficos}

Os resultados dos parâmetros alveográficos (Tabela 5) das farinhas e das misturas indicaram que a massa feita com FT apresentou maiores valores de tenacidade (parâmetro P), extensibilidade (parâmetro L) e força (parâmetro $\mathrm{W}$ ) em relação a STD, sendo os respectivos valores de $122 \mathrm{~mm}$ e $97 \mathrm{~mm}$ para o parâmetro $\mathrm{P}$, de $49 \mathrm{~mm}$ e $28 \mathrm{~mm}$ para o parâmetro L, e de 258 e $1211^{-4} \mathrm{~J}$ para o parâmetro $\mathrm{W}$. Conseqüentemente, os valores de $\mathrm{P}, \mathrm{L}$ e W diminuíram, conforme foi acrescentada a STD na mistura das farinhas. Quanto à relação $\mathrm{P} / \mathrm{L}$, foi observado um aumento no valor quando a STD foi incorporada em maiores proporções nas misturas. O valor da relação P/L foi de 2,49 para a FT e de 3,46 para a STD. O maior valor da relação P/L para a STD é indicativo de uma farinha muito tenaz em relação à sua extensibilidade. Entretanto, a FT mostrou ser mais equilibrada na relação tenacidade/elasticidade.

TABELA 5. Parâmetros alveográficos das misturas de farinha e semolina.

\begin{tabular}{|c|c|c|c|c|}
\hline FT/STD ${ }^{1}$ & $\begin{array}{c}\mathrm{P} \\
(\mathrm{mm})\end{array}$ & $\begin{array}{c}\mathrm{L} \\
(\mathrm{mm})\end{array}$ & $\begin{array}{c}\text { W } \\
\left.\left(10^{-4} \mathrm{~J}\right)\right)\end{array}$ & $\mathrm{P} / \mathrm{L}$ \\
\hline $100 / 0$ & $122 a$ & $49 a$ & $258 a$ & $2,49 c$ \\
\hline $80 / 20$ & $125 a$ & $45 a b$ & $245 b$ & $2,78 b c$ \\
\hline $60 / 40$ & $114 a b$ & $42 b$ & $210 c$ & $2,71 b c$ \\
\hline $40 / 60$ & $117 a b$ & $33 c$ & $175 d$ & $3,37 a$ \\
\hline $20 / 80$ & $103 c$ & $33 c$ & $152 e$ & $3,12 a b$ \\
\hline $0 / 100$ & $97 c$ & $28 d$ & $121 f$ & $3,46 a$ \\
\hline
\end{tabular}

\section{5 - Massas alimentícias frescas}

\subsection{1 - Cor e parâmetros do tempo ótimo de co- zimento}

Nas massas frescas, os valores minimos $(9,52 \%)$ e maximo $(11,74)$ do parâmetro $b$, foram para os produtos elaborados com FT e STD, respectivamente (Tabela 6). Em termos de porcentagem, isto significa que a massa feita com STD teve 18,9\% de coloração amarela, mas intensa em relação ao produto feito com FT. A maior intensidade da cor amarela na massa fresca elaborada com STD é uma característica altamente desejada no produto, pois esse é um dos atrativos visuais de maior influência na aceitação das massas frescas. Por outro lado, não existiu variação significativa $(\mathrm{p}<0.05)$ na cor das massas alimentícias preparadas com 60 e $80 \%$ de STD, em função do tempo de armazenamento (dias 0, 1, 2 e 3). Entretanto, a partir do dia 1 de armazenamento, já existiu diferença estatistica $(\mathrm{p}<0.05)$ nas amostras preparadas com 100, 80 e 60\% de FT.

\subsection{2 - Tempo ótimo de cozimento}

O tempo ótimo de cozimento foi maior (6min.) para a massa fresca preparada com 100\% de FT e com a mistu- 
ra contendo $20 \%$ de STD. Por outro lado, as massas frescas preparadas com $100 \%$ de STD e as demais misturas contendo STD tiveram um tempo de cozimento de $5 \mathrm{~min}$.

Os produtos preparados com 100\% de FT e da mistura com $80 \%$ de FT e $20 \%$ de STD perderam a firmeza quando se atingiu o tempo ótimo de cozimento. Além disso, conforme se incrementou a proporção de STD nas misturas, os produtos apresentaram textura firme ao atingir o tempo ótimo de cozimento, o qual é uma característica de ótima qualidade nos macarrões.

O tempo ótimo de cozimento foi aumentando gradualmente com o tempo de armazenamento. O tempo ótimo de cozimento para a massa fresca preparada com $100 \%$ de FT foi de $6 \mathrm{~min}$. no dia 0, e mudou a $7 \mathrm{~min}$. a partir do dia 1 de armazenamento. Já os produtos elaborados com 100\% de STD e as misturas contendo diferentes proporções de FT e STD atingiram 6min. no 3 dia de armazenamento. O comportamento de aumento no tempo de cozimento provavelmente foi devido a uma pequena perda de umidade residual dos produtos, a qual se refletiu no endurecimento das massas.

\subsection{3 - Ganho de peso e aumento de volume}

Com relação ao peso ganho depois do cozimento (Tabela 6), os valores variaram de 1,82 a 2,01, apresentando valores muito parecidos entre os diferentes tratamentos, e não tendo variação significativa $(\mathrm{p}<0.05)$ nos produtos em função do tempo de armazenamento.

As massas frescas apresentaram pouca variação nos valores de aumento de volume, mas as variações não foram estatisticamente diferentes (produtos com 100, 80, 20 e $0 \%$ de farinha de trigo comum) (Tabela 6). Pode se dizer que esta variável de resposta avaliada não tem grande influência dentro dos parâmetros de qualidade das massas avaliadas.

\subsection{4 - Perda de sólidos na água de cozimento}

A perda de sólidos (PS) teve uma perda de sólidos na água de cozimento menor a $6 \%$ nos diferentes tratamentos (Tabela 6). Isto é um fato importante, pois segundo a classificação de HUMMEL [21], todos os produtos elaborados neste estudo podem ser considerados como massas frescas de qualidade muito boa.

Os maiores valores de PS corresponderam às massas frescas feitas com maiores proporções de STD, que poderiam ter sido ocasionados por uma provável maior quantidade de amido danificado (não analisado) presente na semolina. DEXTER \& MATSUO [19] e KIM et al. [18] explicaram que, quando os produtos de semolina tinham maior conteúdo de amido danificado, também tinham maior conteúdo de perda de sólidos após o cozimento. Mesmo assim, a porcentagem de PS foi muito baixa em todas as amostras, incluindo as que foram feitas com STD.

\subsection{5 - Textura}

Outro parâmetro importante considerado como atributo de qualidade e a textura firme da massa (Tabela
6). Foi observada grande diferença entre o produto feito com $100 \%$ de FT $(1,22 \mathrm{~kg})$ e STD $(2,38 \mathrm{~kg})$ no primeiro dia de armazenamento. Foi observado também, que a mudança em textura foi a partir da adição de $20 \%$ de STD.

Em função do tempo de armazenamento na textura, também foi observado um comportamento similar ao de tempo ótimo de cozimento. Os produtos feitos com maiores proporções de FT apresentaram pequenas mudanças na textura, o que foi mais pronunciado nos tratamentos com $100 \%$ de FT e com os produtos feitos com $80 \%$ e $60 \%$ de FT. A farinha de trigo comum normalmente retrograda mais rapidamente, quando comparadas com os produtos feitos de semolina de trigo durum, devido ao fato, de que a rede protéica que envolve ao amido do trigo durum faz proteção à perda de umidade e recristalização das cadeias de amilose, durante o armazenamento. Já os produtos feitos com FT comum não tem uma rede protéica forte que envolve ao amido. Então tem perda mais rápida de água e as cadeias de amilose tem mais facilidade para unir-se novamente, causando a recristalização, que é uma manifestação da retrogradação.

TABELA 6. Parâmetros de cozimento e cor das massas alimentícias.

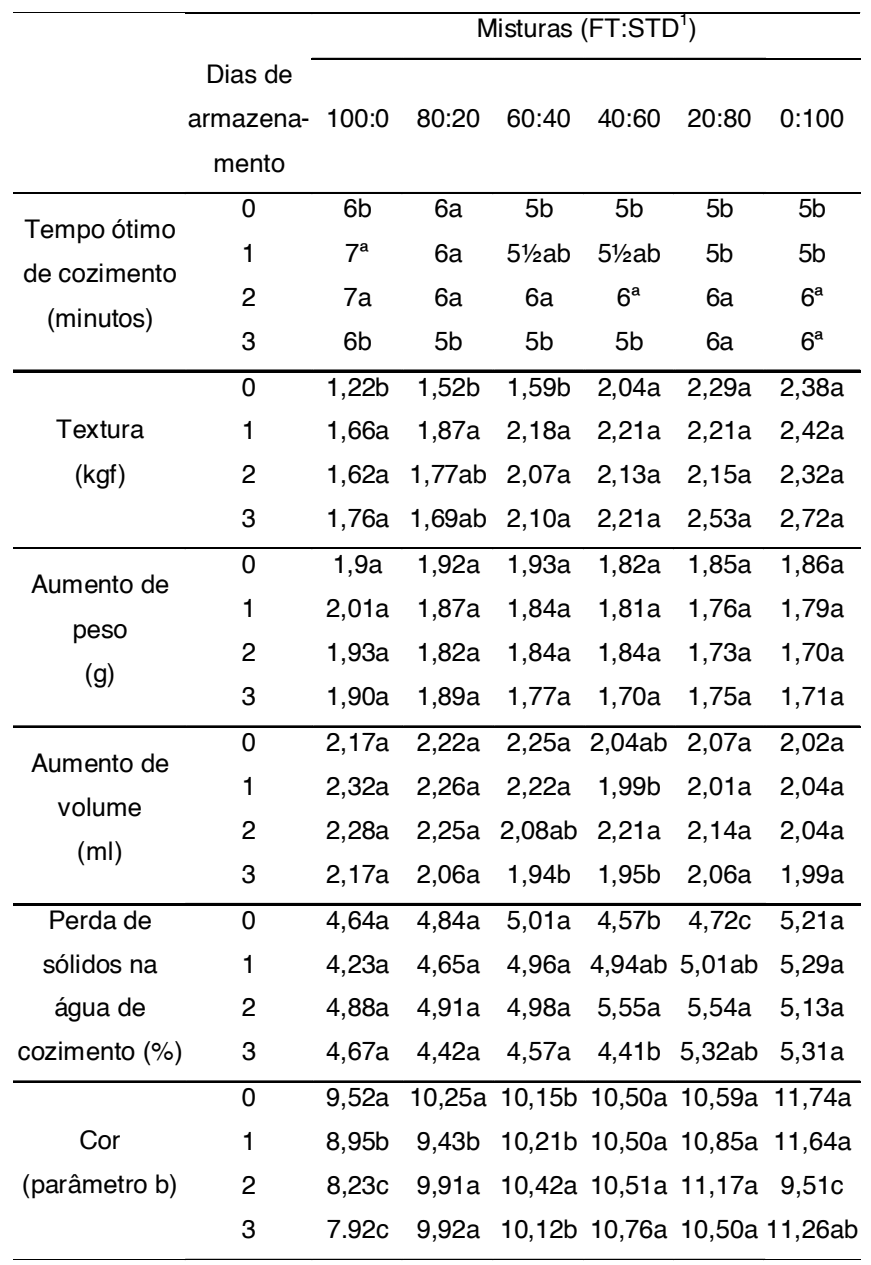

$\overline{\text { Letras diferentes na mesma coluna significa que são estatisticamente diferentes }}$ (p<0.05).

1. FT. Farinha de trigo tenro; STD: Semolina de trigo durum. 


\section{4 - CONCLUSÕES}

- Os melhores atributos de qualidade foram observados nas massas frescas feitas com 100\% de semolina de trigo durum. As misturas testadas que apresentaram características de boa qualidade foram as preparadas com as porcentagens de substituição de $80 \%$ de STD na FT, seguida da preparada com $60 \%$ de substituição de STD na FT.

- A massa fresca feita com 100\% de FT e com nível de substituição de $20 \%$ de STD na FT apresentaram características com qualidade inferior em termos dos atributos de firmeza, e atrativo visual (em função da intensidade da cor amarela).

- Nos três dias de armazenamento, os produtos com $60 \%$ e $80 \%$ de substituição de STD na FT e os produtos preparados com 100\% de STD, apresentaram poucas variações na textura, obtendo-se produtos firmes após o cozimento.

- Os produtos com maior porcentagem de STD - acima de 40\% - apresentaram melhores propriedades de manipulação, devido ao fato de serem produtos mais firmes e mais soltos, em relação aos que foram feitos somente com FT e com baixas proporções de STD.

\section{5 - REFERÊNCIAS BIBLIOGRÁFICAS}

[1] AACC. American Association of Cereal Chemists. Approved Methods. St. Paul Minn. 1995.

[2] AACC. American Association of Cereal Chemists. Approved Methods. St. Paul Minn. 1983.

[3] BAKSHI, A.K.; BAINS, G.S. Study of the Physicochemical, rheological, baking and noodle quality of improved durum and bread wheat cultivars. J. Food Sci. Technol., v. 24, n. 5, p. 217-221, 1987.

[4] BANASIK, O.J. Pasta processing. Cereal Foods World. v. 26, n. 4, p. 166-169, 1981.

[5] BARONI, D. Manufacture of pasta products. In: FABRIANI, G.; LINTAS, C. DURUM. Chemistry and Technology. American Assoc. of Cereal Chemists, Inc. St. Paul, Minn., USA, 1988.

[6] BLIGH, E.G.; DYER, W.J. A rapid method of total lipid extraction and purification. Can. J. Biochem Physiol, v. 37, p. 911-917, 1959.

[7] BOYACIOGLU, M.H.; D’APPOLONIA, B.L. Characterization and utilization of durum wheat for breadmaking. I. Comparison of chemical, rheological, and baking properties between bread wheat flours and durum wheat flours. Cereal Chem., v. 71, n. 1, p. 21-28, 1994.

[8] CIACCO, C.F.; CHANG, Y.K. Como fazer massas. Icone Editora. Editora da UNICAMP. 1986.

[9] CUBBADA, R. Evaluation of durum wheat, semolina and pasta in Europe. In: FABRIANI, G.; LINTAS, C. DURUM. Chemistry and Technology. American Assoc. of Cereal Chemists, Inc., St. Paul Minn., USA. 1988.

[10] D,APPOLONIA, B.L. Types of farinograph curves and factors affecting them. In: The Farinograph Handbook. $3^{\text {rd }}$ ed., B.L.D'APPOLONIA., W.H. KUNERTH, eds. American Association of Cereal Chemists. St. Paul, MN, USA.
[11] D`EGIDIO, M.G.; MARIANI, B.M.; NARDI, S.; NOVARO, P.; CUBADDA, R. Chemical and technological variables and their relationships: a predective equation for pasta cooking quality. Cereal Chem., v. 67, n. 3, p. 275-281, 1990.

[12] DEXTER, J.E.; MATSUO, R.R. Influence of protein content on some durum wheat quality parameters. Canadian J. Plant Sci., v. 57, n. 3, p. 717-727. 1977.

[13] DEXTER, J.E.; MATSUO, R.R. Relationship between durum wheat protein properties and pasta dough rheology and spaghetti cooking quality. J. Agric. Food Chem., v. 28, n. 5, p. 899-902. 1980.

[14] DEXTER, J.E.; MATSUO, R.R.; MORGAN, B.C. Spaghetti stickiness: Some factors influencing stickiness and relationship to other cooking quality characteristics. J. Food Sci., v. 48, n. 5, p. 139-142, 1983.

[15] DEXTER, J.E.; MATSUO, R.R.; MARTIN, D.G. The relationship of durum wheat test weight to milling performance and spaghetti quality. Cereal Foods World, v. 32, n. 10, p. 772-777, 1987.

[16] DEXTER, J.E.; MARTIN, D.G.; MATSUO, R.R. The effect of roll flute orientation on durum wheat semolina quality. Canadian Institute of Food Science and Technology Journal., v. 21, n. 2, p. 187-193, 1988.

[17] DICK, J.W. Rheology of durum. In: FARIDI, H. ed. Rheology of wheat products. American Association of Cereal Chemists, St. Paul, MN., 1985, p. 219-240.

[18] DONELLY, B.J. Pasta products: Raw material, technology, evaluation. Macaroni Journal, v. 61, n. 1, p. 6-18, 1979.

[19] GALVANI, A. Avaliação das características físico-químicas, reológicas e de qualidade de espaguete produzido com farinhas obtidas a partir de nove genótipos de trigo provenientes de cruzamentos entre T. aestivum L. e T. durum L. Campinas, 1996. Dissertação (Mestrado em Tecnologia de Alimentos). Faculdade de Engenharia de Alimentos, UNICAMP.

[20] HOSENEY, R.C.; ROGERS, D.E. The formation and properties of wheat flour doughs. Food Science and Nutrition, v. 26,n. 2, p. 73-93, 1990.

[21] HUMMEL, C. Macaroni products: manufacture, processing and packing. London: Food Trade Press, Ltd., 1966, 287p.

[22] IRVINE, G.N.; BRADLEY, J.W.; MARTIN, G.C. A farinograph technique for macaroni doughs. Cereal Chem., v. 38, n. 2, p. 153-164, 1961.

[23] KIM, H.I.; SEIB, P.A.; POSNER, E.; DEYOE, C.W.; YANG, H.C. Milling hard red winter wheat to flour: Comparison of cooking quality and color of flour and semolina spaghetti. Cereal Foods World, v. 31, n. 11, p. 810-819, 1986.

[24] MATSUO, R.R.; BRADLEY, J.W.; IRVINE, G.N. Effect of protein content on the cooking quality of spaghetti. Cereal Chem., v. 49, n. 6, p. 707-711, 1972.

[25] PANOZZO, J.F.; MCCORMICK, K.M. The rapid viscoanalyser as a method of testing for noodle quality in a wheat breeding programme. J. Cereal Sci., v. 177, n. 1, p. 25-32, 1993.

[26] PROSKY, L.; ASP NILS-GEORG.; SCHEIZER, F.T.; DEVRIES, W.J.; FURDA, I. Determination of Insoluble, Soluble and total Dietary Fiber in Foods and Food Products: Interlaboratory Study. J. Assoc. Off. Anal. Chem., v. 71, n. 5, p. 1017-1023, 1998.

[27] RAHIM, A.; PRABHAVATHI, C.; HARIDAS, RAOS, P.; SHUPPALEKAR, S. R. Suitability of indian durum wheat for semolina milling and vermicelli preparation. J. Food Sci. Techn., v. 139, n. 5, p. 249-252, 1976. 
[28] TOEPFER, E.W.; POLANSKY, M.M.; EHEART, J.F.; SLOVER, H.T.; MORRIS, E.R.; HEPBURN, F.N.; QUACKENBUSH, F.W. Nutrient composition of selected wheat products. Cereal Chem., v. 49, n. 2, p. 173-186, 1972.

[29] WYLAND, A.R.; D’APPOLONIA, B.L. Influence of drying temperature and farina blending on spaghetti quality. Cereal Chem., v. 59, n. 3, p. 199-201, 1982.

\section{6 - AGRADECIMENTOS}

À empresa CARGILL FOODS do Brasil pelo fornecimento das matérias-primas e apoio para a realização da pesquisa. À FAPESP pelo apoio financieiro através da bolsa de pós-doutoramento ao pesquisador Dr. Héctor E. Martínez Flores. À Silvia Maria Kuniyuki, estudante da FEA-UNICAMP, pela participação durante a realização da fase experimental do projeto. 